\title{
Anxiety, depression, and regret of donation in living kidney donors
}

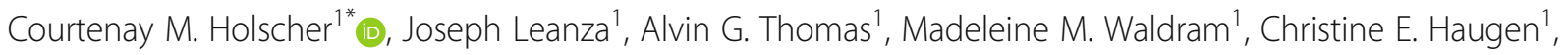
Kyle R. Jackson', Sunjae Bae ${ }^{1,2}$, Allan B. Massie ${ }^{1,2}$ and Dorry L. Segev ${ }^{1,2}$

\begin{abstract}
Background: Previous studies have reported a wide range of prevalence of post-donation anxiety, depression, and regret in living kidney donors (LKDs). It is also unclear what risk factors are associated with these outcomes.

Methods: We screened 825 LKDs for anxiety and depression using 2-item GAD-2 and PHQ-2 scales and asked about regret.

Results: Overall, 5.5\% screened positive for anxiety, 4.2\% for depression, and 2.1\% reported regretting their donation. While there was moderate correlation between positive anxiety and depression screens $(r=0.52)$, there was no correlation between regret and positive screens ( $r<0.1$ for both). A positive anxiety screen was more likely in LKDs with a positive depression screen (adjusted relative risk [aRR] 13.72, 95\% confidence interval [CI] 6.78-27.74, $p<0.001$ ). Similarly, a positive depression screen was more likely in LKDs with a positive anxiety screen (aRR 19.50, $95 \% \mathrm{Cl} 6.94-54.81, p<0.001$ ), as well as in those whose recipients experienced graft loss (aRR 5.38, 95\% Cl 1.29-22. $32, p=0.02$ ). Regret was more likely in LKDs with a positive anxiety screen (aRR 5.68, 95\% Cl 1.20-26.90, $p=0.03$ ). This was a single center cross-sectional study which may limit generalizability and examination of causal effects. Also, due to the low prevalence of adverse psychosocial outcomes, we may lack power to detect some associations between donor characteristics and anxiety, depression, or regret.
\end{abstract}

Conclusions: Although there is a low prevalence of anxiety, depression, and regret of donation among LKDs, these are interrelated conditions and a positive screen for one condition should prompt evaluation for other conditions.

Keywords: Kidney transplantation, Living donors, Donor follow-up, Quality of life, Anxiety, Depression, Mental health screening, Psychiatric screening, GAD-2, PHQ-2

\section{Background}

Anxiety and mood disorders affect 18.1 and $9.5 \%$ of US adults per year, and have been associated with higher rates of disability, non-compliance, acute illness, exacerbations of chronic illness, and even death [1-6]. Although pre-donation psychiatric assessments for all living kidney donors (LKDs) are mandated in the United States by the Organ Procurement and Transplantation Network (OPTN) [7]. LKDs still experience adverse psychosocial outcomes post-donation [8-11]. Not only is this a bad situation for the donor: when LKDs experience adverse psychosocial outcomes, the transplant community is also

\footnotetext{
* Correspondence: cholsch1@jhmi.edu

${ }^{1}$ Department of Surgery, Johns Hopkins University School of Medicine, 2000

E. Monument St., Baltimore, MD 21205, USA

Full list of author information is available at the end of the article
}

at risk of losing advocates for living kidney donation. However, our understanding of post-donation anxiety, depression, and regretting the donation remains poorly understood.

First, the post-donation prevalence of these conditions remains unclear, with wide ranges reported of 6-67\% for anxiety, 5-23\% for depression, and 0-7\% for regretting the donation $[9,12-21]$. Beyond unclear prevalence estimates, our understanding is limited by a paucity of studies identifying risk factors for these conditions. In a cohort of 45 Portuguese donors, $67 \%$ had post-donation anxiety; however, risk factors for anxiety were not studied [19]. Wiedebusch et al. studied 161 German LKDs and found a $21 \%$ prevalence of anxiety and that both anxiety and depression were associated with worse quality of life [21]. A higher risk of depression has been

(C) The Author(s). 2018 Open Access This article is distributed under the terms of the Creative Commons Attribution 4.0 International License (http://creativecommons.org/licenses/by/4.0/), which permits unrestricted use, distribution, and 
reported in unmarried LKDs, those with a history of pre-donation depression, greater financial burden, recipient graft failure or death, and short-term medical complications or re-hospitalizations [16, 18, 19, 22]. Though prior studies have reported that most LKDs would willingly donate again [8-10, 12, 13, 21, 23-34], it is intuitive that those donors with negative psychosocial outcomes post-donation might be at higher risk for regretting their donation.

To better understand prevalence and risk factors associated with anxiety, depression, and regret in LKDs, we screened a cohort of LKDs using the 2-item Generalized Anxiety Disorder scale (GAD-2), the 2-item Patient Health Questionnaire (PHQ-2) scale for depression, and a single-question survey on regret of donation.

\section{Methods}

\section{Study population}

The Wellness and Health Outcomes in Live Donors (WHOLE-Donor) cohort is an ongoing study of living kidney donors who underwent donor nephrectomy at Johns Hopkins Hospital between 1982 and 2015, for which enrollment began in 2011. Participants consented to quality of life surveys and a survey detailing medical, surgical, hospitalization, psychiatric, and social history. This is a cross-sectional study of participants' first survey responses at the time of enrollment from 2011 to 2017. The Johns Hopkins Medicine Institutional Review Board (NA_00044282) approved this study.

\section{Outcomes}

We defined post-donation anxiety as a score of 3 or higher on the GAD-2 anxiety screen, as previously defined and validated [35]. We defined post-donation depression as a score of 3 or higher on the PHQ-2 depression screen, as previously defined and validated [36, 37]. Post-donation regret was evaluated using the question, "Given the chance, would you offer to donate your kidney again?" We defined post-donation regret as those who gave negative responses on the 5-point Likert scale, i.e. "probably not" or "definitely not."

\section{Risk factors}

Demographic characteristics and medical history including comorbid diagnoses and medications were self-reported by participants. Antidepressants, anti-anxiety medications, medications for obsessive-compulsive disorder, and medications for bipolar disorder were considered psychiatric medications. Difficulty changing or obtaining new health insurance or life insurance were self-reported. A socioeconomic status (SES) index corresponding to each participant's ZIP code was generated using the method described by the Agency for Healthcare Research and Quality, based on crowding, property value, poverty levels, educational attainment, employment, and median household income at the ZIP code level [38]. Participants were classified as having below median SES or above median SES within our study population based on the ZIP code they reported. A random subset of 204 participants also completed a survey module which included questions about relationship with recipient and recipient graft and vital status.

\section{Model selection}

We used modified Poisson regression models to describe the relative risk of covariates for each of the outcomes [39]. In order to select the best subset of covariates, we compared models including different subsets of covariates using the Akaike information criterion, an indicator of the relative quality of models. The covariates were age, number of years since donation, gender, African American race, college education or higher, married or living with a partner, employment status, current or former tobacco smoking, socioeconomic status, hypertension, diabetes, chronic kidney disease, hyperlipidemia, diagnosis of depression, diagnosis of another psychiatric illness, development of another comorbidity, and development of any comorbidity. Additionally, positive GAD-2 screen, positive PHQ-2 screen, and reporting regret of donation were included in each subset of covariates except for the model where that risk factor was considered the outcome.

Because 204 participants were randomized to the model containing questions about recipient outcomes, we initially excluded these 204 from covariate selection described above, and created a model offset to constrain covariate coefficients to the values determined by the initial regression models. In order then to include recipient outcomes as risk factors for anxiety, depression, and regret of donation, we used the model offset from the prior step with robust standard errors to run Poisson regression models. By using this method to constrain coefficients, we were able to maintain power but also study the risk factors assessed in a survey module administered to a subset of our study population.

\section{Statistical analysis}

Descriptive statistics are reported using $\mathrm{t}$ tests, chi-square tests, and Pearson's correlation coefficient. An $\alpha$ of 0.05 was considered significant. Confidence intervals are reported as per the method of Louis and Zeger [40]. Analyses were performed using Stata 14.2/SE for Windows (College Station, Texas).

\section{Results}

\section{Study population}

Among 825 participants, median (interquartile range [IQR]) time since donation was 6 (3-10) years, median (IQR) age at survey completion was $46(36-54)$ years, 
63.5\% of participants were female, $10.1 \%$ were African American, $66.7 \%$ had some college education or higher, $70.9 \%$ were married or living with their partner, and $63.2 \%$ were employed full-time (Table 1). Overall $47.0 \%$ had developed one or more comorbid illnesses including high cholesterol (19.8\%), hypertension (15.2\%), diabetes (3.6\%), chronic kidney disease (1.7\%), depression (13.3\%), other psychiatric disorders (5.3\%), and other diseases (39.6\%) including thyroid disorders and hematologic disorders.
There were 436 participants who responded to questions about insurance (question response rate 52.8\%); of them, 44 (10.1\%) reported difficulty obtaining or changing life or health insurance (Table 1).

Of the 204 participants who participated in the survey module that included questions about their recipient, $21.1 \%$ reported donating to their sibling, $20.1 \%$ reported donating to a spouse or partner, $14.2 \%$ reported donating to a friend, and $12.2 \%$ reported donating to a child;

Table 1 Characteristics of living kidney donors

\begin{tabular}{|c|c|c|c|c|}
\hline & All & Anxiety & Depression & Regret \\
\hline & $n=825$ & $n=41$ & $n=31$ & $n=16$ \\
\hline Age at survey completion, median years (IQR) & $46(36-54)$ & $44(36-51)$ & $44(38-55)$ & $39(34-55)$ \\
\hline Time since donation, median years (IQR) & $6(3-10)$ & $6(3-8)$ & $6(3-11)$ & $7(5-10)$ \\
\hline BMI at survey completion, median (IQR) & $26(24-30)$ & $26(24-30)$ & $26(23-29)$ & $28(25-31)$ \\
\hline Female & $524(63.5 \%)$ & $26(63.4 \%)$ & $21(67.7 \%)$ & $12(75.0 \%)$ \\
\hline African American & $83(10.1 \%)$ & $4(9.8 \%)$ & $4(12.9 \%)$ & $5(31.2 \%)^{*}$ \\
\hline Some college education or higher & $550(66.7 \%)$ & $21(51.2 \%)^{*}$ & $11(35.5 \%)^{*}$ & $10(62.5 \%)$ \\
\hline Married or living with partner & $583(70.9 \%)$ & $21(51.2 \%)^{*}$ & $14(45.2 \%)^{*}$ & $7(43.8 \%)^{*}$ \\
\hline Current or former smoker & $309(37.4 \%)$ & $24(58.5 \%)^{*}$ & $18(58.1 \%)^{*}$ & $8(50.0 \%)$ \\
\hline Low SES by ZIP code of residence & $360(50.1 \%)$ & $21(61.8 \%)$ & $17(63.0 \%)$ & $5(50.0 \%)$ \\
\hline \multicolumn{5}{|l|}{ Employment status } \\
\hline Full-time & $521(63.2 \%)$ & $27(65.8 \%)$ & $18(58.1 \%)$ & $9(56.2 \%)$ \\
\hline Part-time & $94(11.4 \%)$ & $7(17.1 \%)$ & $3(9.7 \%)$ & $1(6.2 \%)$ \\
\hline Retired & $129(15.6 \%)$ & $3(7.3 \%)$ & $5(16.1 \%)$ & $4(25.0 \%)$ \\
\hline Unemployed & $81(9.8 \%)$ & $4(9.8 \%)$ & $5(16.1 \%)$ & $2(12.5 \%)$ \\
\hline Any comorbidity & $388(47.0 \%)$ & $23(56.1 \%)$ & $20(64.5 \%)$ & $11(68.8 \%)$ \\
\hline Hypertension & $125(15.2 \%)$ & $11(26.8 \%)^{*}$ & $12(38.7 \%)^{*}$ & $3(18.8 \%)$ \\
\hline Diabetes & $29(3.6 \%)$ & $1(2.6 \%)$ & $2(6.7 \%)$ & $1(6.2 \%)$ \\
\hline Chronic kidney disease & $14(1.7 \%)$ & 0 & 0 & 0 \\
\hline High cholesterol & $163(19.8 \%)$ & $9(22.0 \%)$ & $8(25.8 \%)$ & $6(37.5 \%)$ \\
\hline Diagnosis of depression & $103(13.3 \%)$ & $9(26.5 \%)$ & $10(35.7 \%)^{*}$ & $5(31.2 \%)$ \\
\hline Diagnosis of other psychiatric disorder & $44(5.3 \%)$ & $4(9.8 \%)$ & $3(9.7 \%)$ & $2(12.5 \%)$ \\
\hline Other comorbidity & $327(39.6 \%)$ & $18(43.9 \%)$ & $16(51.6 \%)$ & $9(56.2 \%)$ \\
\hline Any psychiatric medication use & $135(16.4 \%)$ & $14(34.2 \%)^{*}$ & $9(29.0 \%)^{*}$ & $3(18.8 \%)$ \\
\hline Trouble obtaining or changing insurance ${ }^{a}$ & $44(10.1 \%)$ & $2(7.7 \%)$ & $1(5.3 \%)$ & $3(30.0 \%)^{*}$ \\
\hline \multicolumn{5}{|l|}{ Relationship to recipient ${ }^{b}$} \\
\hline Child & $25(12.2 \%)$ & $3(25.0 \%)$ & $3(23.1 \%)$ & $1(20.0 \%)$ \\
\hline Parent & $17(8.3 \%)$ & 0 & 0 & 0 \\
\hline Sibling & $43(21.1 \%)$ & 0 & $1(7.7 \%)$ & $2(40.0 \%)$ \\
\hline Spouse/partner & $41(20.1 \%)$ & $2(16.7 \%)$ & $1(7.7 \%)$ & $1(20.0 \%)$ \\
\hline Friend & $29(14.2 \%)$ & $4(33.3 \%)$ & $3(23.1 \%)$ & 0 \\
\hline Other & $49(24.0 \%)$ & $3(25.0 \%)$ & $5(38.5 \%)$ & $1(20.0 \%)$ \\
\hline Recipient graft loss ${ }^{\mathrm{b}}$ & $20(14.1 \%)$ & 0 & $2(28.6 \%)$ & $1(50.0 \%)$ \\
\hline Recipient mortality ${ }^{\mathrm{b}}$ & $61(29.9 \%)$ & $5(41.7 \%)$ & $6(46.2 \%)$ & $3(60.0 \%)$ \\
\hline
\end{tabular}

${ }^{*} p<0.05$ compared to subjects without anxiety, depression, or regret, respectively

${ }^{a} \mathrm{~A}$ total of 436 subjects responded to a question about experience with life or health insurance

${ }^{\mathrm{b}} \mathrm{A}$ total of 204 subjects participated in the survey module which included questions about recipients 
$29.9 \%$ reported that their recipient had since died and $14.1 \%$ reported that their recipient had experienced graft loss.

\section{Prevalence and correlation of anxiety, depression, and regret}

Forty one (5.5\%) of 742 respondents screened positive for anxiety (89.9\% response rate). Respondents to the anxiety screen were similar to non-respondents in age, race, education, employment status, and marital status, but were less likely female (62.4\% vs. $73.5 \%, p=0.046) .31$ (4.2\%) of 741 respondents screened positive for depression $(89.8 \%$ response rate). Respondents to the depression screen were similar to non-respondents in age, gender, race, education, employment status, and marital status. 16 (2.1\%) of 749 respondents reported feeling regret of their donation (90.8\% response rate). Respondents to the question about regret were similar to non-respondents in age, gender, race, education, employment status, and marital status. While there was moderate correlation between a positive anxiety screen and a positive depression screen $(r=0.52)$, there was no correlation between regret and anxiety or depression $(r<0.1$ for both, Table 2$)$.

\section{Risk factors for anxiety}

Compared to subjects who did not screen positive on the GAD-2, subjects with a positive GAD-2 screen were less likely to have some college education or higher (51.2\% vs. $67.5 \%, p=0.03)$, less likely to be married or living with a partner $(51.2 \%$ vs. $72.6 \%, p=0.003)$, more likely to be a current or former smoker (58.5\% vs. $37.5 \%$, $p=0.007)$, and more likely to have hypertension $(26.8 \%$ vs. $15.3 \%, p<0.001$, Table 1$)$. In multivariable analysis, subjects with a positive PHQ-2 depression screen were more likely to have a positive GAD-2 anxiety screen (adjusted relative risk [aRR] $6.7813 .722_{27.74}, p<0.001$ ), while those who donated more recently were less likely to have a positive GAD-2 (per year, aRR ${ }_{0.89} 0.93_{0.98}, p=0.006$, Table 3).

\section{Risk factors for depression}

Compared to subjects who did not screen positive on the PHQ-2, subjects with a positive PHQ-2 screen were less likely to have some college education or higher (35.5\% vs. $68.0 \%, p<0.001$ ), less likely to be married or living with a partner $(45.2 \%$ vs. $72.2 \%, p=0.001)$, more

Table 2 Correlation between anxiety, depression, and regret following living kidney donation

\begin{tabular}{llcl}
\hline & Anxiety & Depression & Regret \\
\hline Anxiety & 1.00 & & \\
Depression & 0.52 & 1.00 & \\
Regret & 0.05 & 0.02 & 1.00 \\
\hline
\end{tabular}

Table 3 Risk factors associated with positive GAD-2 anxiety screen in living kidney donors. Adjusted relative risk presented with $95 \%$ confidence interval. Model adjusted for risk factors included in the table

\begin{tabular}{lll}
\hline & Adjusted Relative Risk & $p$-value \\
\hline Positive PHQ-2 screen & $6.7813 .72_{27.74}$ & $<0.001$ \\
Years since donation (by year) & $0.890 .93_{0.98}$ & 0.006 \\
Married/living with a partner & $0.260 .52_{1.05}$ & 0.07 \\
Hypertension & $0.961 .54_{2.48}$ & 0.08 \\
Recipient alive & $0.380 .82_{1.78}$ & 0.6 \\
\hline
\end{tabular}

likely to be a current or former smoker $(58.1 \%$ vs. $37.5 \%$, $p=0.02)$, more likely to have hypertension $(38.7 \%$ vs. $14.8 \%, p<0.001$ ), and more likely to report having been diagnosed with depression by a doctor or other healthcare professional ( $35.7 \%$ vs. $12.2 \%, p=0.004$, Table 1$)$. In multivariable analysis, subjects with a positive GAD-2 anxiety screen (aRR 6.94 $19.5054 .81, p<0.001$ ) and those whose recipient had experience graft loss (aRR ${ }_{1.29} 5.38 \quad 22.32$, $p=0.02$ ) were more likely to have a positive PHQ-2 depression screen (Table 4).

\section{Risk factors for regret}

Compared to subjects who did not report regret, subjects who reported regretting their donation were more likely to be African American (31.2\% vs. 9.7\%, $p=0.005$ ), less likely to be married or living with a partner $(43.8 \%$ vs. $72.0 \%, p=0.01$ ), and more likely to report having trouble obtaining or changing health or life insurance $(30.0 \%$ vs. $10.2 \%, p=0.04$, Table 1 ). In multivariable analysis, subjects with a positive GAD-2 anxiety screen were more likely to regret donation (aRR ${ }_{1.20} 5.68_{26.90}, p=0.03$, Table 5).

\section{Discussion}

In this cohort of 825 LKDs interviewed at a median of 6 years after donation, $5.5 \%$ screened positive for anxiety, $4.2 \%$ screened positive for depression, and $2.1 \%$ reported regretting their donation. We found moderate correlation between positive anxiety and depression screens $(r=0.52)$. A positive anxiety screen was associated with a nearly

Table 4 Risk factors associated with positive PHQ-2 depression screen in living kidney donors. Adjusted relative risk presented with $95 \%$ confidence interval. Model adjusted for risk factors included in the table

\begin{tabular}{lll}
\hline & Adjusted Relative Risk & $p$-value \\
\hline Positive GAD-2 screen & $6.9419 .50_{54.81}$ & $<0.001$ \\
Some college education or higher & $0.180 .50_{1.36}$ & 0.2 \\
Married/living with a partner & $0.240 .68_{1.88}$ & 0.4 \\
Hypertension & $0.901 .59_{2.79}$ & 0.1 \\
Diagnosis of depression & $0.481 .45_{4.40}$ & 0.5 \\
Recipient graft loss & $1.295 .38_{22.32}$ & 0.02 \\
\hline
\end{tabular}


Table 5 Risk factors associated with regret of donation in living kidney donors. Adjusted relative risk presented with 95\% confidence interval. Model adjusted for risk factors included in the table

\begin{tabular}{lll}
\hline & Adjusted Relative Risk & $p$-value \\
\hline African American & $0.753 .78_{18.92}$ & 0.1 \\
$\begin{array}{l}\text { Age at survey completion } \\
\text { (per 10 years) }\end{array}$ & $0.580 .98_{1.65}$ & 0.9 \\
Positive GAD-2 screen & $1.205 .68_{26.90}$ & 0.03 \\
$\begin{array}{l}\text { Development of any comorbidity } \\
\text { Trouble obtaining or changing }\end{array}$ & $0.351 .53_{6.74}$ & 0.6 \\
insurance & $0.753 .13_{12.98}$ & 0.1 \\
Recipient graft loss & $0.574 .59_{36.81}$ & 0.2 \\
\hline
\end{tabular}

20-fold higher risk for positive depression screen and a 5.7-fold higher risk for regret of donation. Similarly, a positive depression screen was associated with a 13.7-fold higher risk for positive anxiety screen. On univariate analysis, college education, marital status, smoking history, and diagnosis of hypertension were associated with anxiety and depression, while African American race, marital status, and insurance problems were associated with regret.

Our finding that $5.5 \%$ of LKDs screen positive for anxiety is similar to the $6 \%$ of a cohort of 48 Australian donors [9], lower than the $21 \%$ with anxiety in a cohort of 161 German LKDs [21], and substantially lower than the $67 \%$ with anxiety in a cohort of 45 Portuguese LKDs [19]. The prevalence of anxiety in LKDs is also substantially lower than a US general population prevalence estimate of $18.1 \%$ [1]. Similar to findings from the RELIVE study, development of comorbid illness, namely hypertension, was associated with both depression and anxiety in our cohort [16].

Our finding of an association between marital status and anxiety, depression, and regret is consistent with a Japanese study which reported that living alone was the single best predictor for depression in kidney recipients [41]. The prevalence of depression in this cohort of 116 Japanese donors was $41.4 \%$, however, much higher than the $4.2 \%$ prevalence in our cohort. Interestingly, though only $4.2 \%$ screened positive for depressive symptoms, $13.3 \%$ reported a history of depression. This is consistent with prior community studies which have found that half of those with a first episode of major depression recover within 3 months $[42,43]$ and that half had no future episodes of major depression [43]. Our finding that age was not associated with anxiety or depression must be considered in the context of conflicting literature. Isotani et al. report better quality of life scores for younger donors, while other groups have reported that younger donors have worse quality of life in a variety of domains [12, 16, 18, 26, 29].
Our finding that $2.1 \%$ of LKDs would not donate again is within the range of reported prevalence of regret, ranging from 0 to $7 \%[8,12,13,21,23-32,44]$. Given the increased emphasis on holistic donor follow-up and support for wellbeing, a benefit of addressing mental health might lead fewer LKDs to regret their donation, as we found a positive anxiety screen was associated with regret.

Our study does have several limitations. The study was conducted in a single center, which may limit the generalizability of our findings. However, the age, sex, and race of our participants is similar to the general population of US donors [45]. Also, despite a sample size of 825 donors and excellent response rate, we may lack power to detect additional associations between donor characteristics and anxiety, depression, or regret of donation in multivariable regression, due to the low prevalence of these outcomes. Additionally, our study used screening tools to describe symptoms of anxiety and depression rather than a diagnostic tool; however, by using a screening tool we were able to capture these symptoms with good sensitivity using the GAD-2 and PHQ-2. Finally, although the cross-sectional nature of our survey prohibits examination of causal effects, the prevalence estimates and risk factors provide insight in LKD follow-up and might help identify those LKDs most in need of formal referral for mental health services.

\section{Conclusions}

In this cohort of 825 LKDs, we found that $5.5 \%$ screened positive for anxiety, $4.2 \%$ screened positive for depression, and $2.1 \%$ reported regret of their decision to donate. Given the growing waitlist and an emphasis on expanding live donation, the finding that some LKDs harbor regret is not only ethically relevant, but also a practical consideration in pre-donation counseling. While the OPTN does not specifically mandate psychosocial follow-up post-donation, they emphasize consideration of donor safety and wellbeing. Our study suggests that psychosocial screening at follow-up may prove especially useful for patients with other psychosocial symptoms, who develop a chronic medical condition after donating, or who lack a proximal social support network.

\section{Abbreviations}

aRR: Adjusted relative risk; BMI: Body mass index; Cl: Confidence interval; GAD-2: Generalized Anxiety Disorder; IQR: Interquartile range; LKD: Living kidney donor; OPTN: Organ Procurement and Transplantation Network; PHQ2: Patient Health Questionnaire; SES: Socioeconomic status; WHOLE: Wellness and Health Outcomes in LivE Donors

\section{Acknowledgements}

We sincerely thank the study participants and the research staff at Johns Hopkins. 


\section{Funding}

This work was supported by a Doris Duke Charitable Foundation Grant 2015055 (PI: Segev), National Institutes of Health (NIH) grants R01DK096008 (PI: Segev), K01DK101677 (PI: Massie), K24DK101828 (PI: Segev), F32DK113719 (PI: Jackson), F32AG053025 (PI: Haugen), F32DK109662 (PI: Holscher), and an American College of Surgeons Resident Research Scholarship (PI: Holscher). The funding bodies had no role in the design of the study; the collection, analysis, and interpretation of data; or in writing the manuscript. The analyses described here are the responsibility of the authors alone and do not necessarily reflect the views or policies of the Department of Health and Human Services, nor does mention of trade names, commercial products or organizations imply endorsement by the U.S. Government.

\section{Availability of data and materials}

The dataset used during the current study is available from the corresponding author on reasonable request.

\section{Authors' contributions}

The authors made the following contributions: $\mathrm{CMH}$ participated in research design, writing of the paper, data analysis, interpretation of analysis, and critical revision; JL participated in research design, data collection, writing of the paper, data analysis, and critical revision; AGT participated in research design, writing of the paper, data analysis, and critical revision; MMW participated in research design, data collection, and critical revision; $\mathrm{CEH}$ participated in writing of the paper, interpretation of analysis, and critical revision; $\mathrm{KJ}$ participated in writing of the paper, interpretation of analysis, and critical revision; SB participated in writing of the paper, interpretation of analysis, and critical revision; ABM participated in research design, interpretation of analysis, and critical revision; and DLS participated in research design, writing of the paper, interpretation of analysis, and critical revision. All authors read and approved the final manuscript.

\section{Ethics approval and consent to participate}

This study was approved by the Johns Hopkins Medicine Institutional Review Board (NA_00044282) and all participants provided written informed consent at enrollment.

\section{Consent for publication}

Not applicable.

\section{Competing interests}

The authors declare they have no competing interests.

\section{Publisher's Note}

Springer Nature remains neutral with regard to jurisdictional claims in published maps and institutional affiliations.

\section{Author details}

${ }^{1}$ Department of Surgery, Johns Hopkins University School of Medicine, 2000 E. Monument St., Baltimore, MD 21205, USA. ²Department of Epidemiology, Johns Hopkins School of Public Health, Baltimore, MD, USA.

\section{Received: 25 July 2018 Accepted: 28 August 2018}

Published online: 04 September 2018

\section{References}

1. Kessler RC, Chiu WT, Demler O, Merikangas KR, Walters EE. Prevalence, severity, and comorbidity of 12-month DSM-IV disorders in the National Comorbidity Survey Replication. Arch Gen Psychiatry. 2005;62(6):617-27.

2. Egede LE. Major depression in individuals with chronic medical disorders: prevalence, correlates and association with health resource utilization, lost productivity and functional disability. Gen Hosp Psychiatry. 2007;29(5):409-16.

3. Roy-Byrne PP, Davidson KW, Kessler RC, Asmundson GJ, Goodwin RD, Kubzansky L, et al. Anxiety disorders and comorbid medical illness. Gen Hosp Psychiatry. 2008;30(3):208-25.

4. Katon W, Lin EH, Kroenke K. The association of depression and anxiety with medical symptom burden in patients with chronic medical illness. Gen Hosp Psychiatry. 2007;29(2):147-55.

5. Rugulies R. Depression as a predictor for coronary heart disease. A review and meta-analysis. Am J Prev Med. 2002;23(1):51-61.
6. Broadhead WE, Blazer DG, George LK, Tse CK. Depression, disability days, and days lost from work in a prospective epidemiologic survey. JAMA. 1990; 264(19):2524-8

7. Network OPaT. OPTN Policies. In: Policy 14: Living Donation: Health Resources and Services Administration. Rockville: U.S. Department of Health and Human Services; 2016.

8. Massey EK, Kranenburg LW, Zuidema WC, Hak G, Erdman RA, Hilhorst M, et al. Encouraging psychological outcomes after altruistic donation to a stranger. Am J Transplant. 2010;10(6):1445-52.

9. Smith GC, Trauer T, Kerr PG, Chadban SJ. Prospective psychosocial monitoring of living kidney donors using the short Form-36 health survey: results at 12 months. Transplantation. 2004;78(9):1384-9.

10. Walton-Moss B, Boulware LE, Cooper M, Taylor L, Dane K, Nolan MT Prospective pilot study of living kidney donor decision-making and outcomes. Clin Transpl. 2007;21(1):86-93.

11. Erim $Y$, Kahraman $Y$, Vitinius F, Beckmann M, Kroncke S, Witzke O. Resilience and quality of life in 161 living kidney donors before nephrectomy and in the aftermath of donation: a naturalistic single center study. BMC Nephrol. 2015;16:164.

12. Giessing M, Reuter S, Schonberger B, Deger S, Tuerk I, Hirte I, et al. Quality of life of living kidney donors in Germany: a survey with the validated short Form-36 and Giessen subjective complaints List-24 questionnaires. Transplantation. 2004;78(6):864-72.

13. Rudow DL, Chariton M, Sanchez C, Chang S, Serur D, Brown RS Jr. Kidney and liver living donors: a comparison of experiences. Prog Transplant. 2005; 15(2):185-91.

14. Clemens KK, Thiessen-Philbrook H, Parikh CR, Yang RC, Karley ML, Boudville $\mathrm{N}$, et al. Psychosocial health of living kidney donors: a systematic review. Am J Transplant. 2006;6(12):2965-77.

15. Virzi A, Signorelli MS, Veroux M, Giammarresi G, Maugeri S, Nicoletti A, et al. Depression and quality of life in living related renal transplantation. Transplant Proc. 2007:39(6):1791-3.

16. Jowsey SG, Jacobs C, Gross CR, Hong BA, Messersmith EE, Gillespie BW, et al. Emotional well-being of living kidney donors: findings from the RELIVE study. Am J Transplant. 2014;14(11):2535-44.

17. Kroencke S, Fischer L, Nashan B, Herich L, Schulz KH. A prospective study on living related kidney donors' quality of life in the first year: choosing appropriate reference data. Clin Transpl. 2012;26(4):E418-27.

18. Lentine KL, Schnitzler MA, Xiao H, Axelrod D, Davis CL, McCabe M, et al. Depression diagnoses after living kidney donation: linking U.S. registry data and administrative claims. Transplantation. 2012;94(1):77-83.

19. Lopes A, Frade IC, Teixeira L, Oliveira C, Almeida M, Dias L, et al. Depression and anxiety in living kidney donation: evaluation of donors and recipients. Transplant Proc. 2011;43(1):131-6.

20. Perez-San-Gregorio MA, Fernandez-Jimenez E, Luque-Budia A, MartinRodriguez A. Anxiety and concerns in Spanish living kidney donor candidates. Int J Psychiatry Med. 2015;50(2):163-77.

21. Wiedebusch S, Reiermann S, Steinke C, Muthny FA, Pavenstaedt HJ, Schoene-Seifert B, et al. Quality of life, coping, and mental health status after living kidney donation. Transplant Proc. 2009;41(5):1483-8.

22. Rodrigue JR, Fleishman A, Vishnevsky T, Whiting J, Vella JP, Garrison K, et al. Development and validation of a questionnaire to assess fear of kidney failure following living donation. Transpl Int. 2014:27(6):570-5.

23. Jacobs CL, Gross CR, Messersmith EE, Hong BA, Gillespie BW, Hill-Callahan P, et al. Emotional and financial experiences of kidney donors over the past 50 years: the RELIVE study. Clin J Am Soc Nephrol. 2015;10(12):2221-31.

24. Binet I, Bock AH, Vogelbach $P$, Gasser $T$, Kiss A, Brunner $F$, et al. Outcome in emotionally related living kidney donor transplantation. Nephrol Dial Transplant. 1997;12(9):1940-8.

25. Clemens K, Boudville N, Dew MA, Geddes C, Gill JS, Jassal V, et al. The longterm quality of life of living kidney donors: a multicenter cohort study. Am J Transplant. 2011;11(3):463-9.

26. Fehrman-Ekholm I, Brink B, Ericsson C, Elinder CG, Duner F, Lundgren G. Kidney donors don't regret: follow-up of 370 donors in Stockholm since 1964. Transplantation. 2000;69(10):2067-71.

27. Frade IC, Fonseca I, Dias L, Henriques AC, Martins LS, Santos J, et al. Impact assessment in living kidney donation: psychosocial aspects in the donor. Transplant Proc. 2008:40(3):677-81.

28. Frade IC, Lopes A, Teixeira L, Rodrigues J, Almeida M, Dias L, et al. Perceptions in living kidney donation: what protagonists think and feel. Transplant Proc. 2011;43(1):39-42. 
29. Isotani S, Fujisawa M, Ichikawa Y, Ishimura T, Matsumoto O, Hamami G, et al. Quality of life of living kidney donors: the short-form 36-item health questionnaire survey. Urology. 2002;60(4):588-92. discussion 92

30. Jacobs C, Johnson E, Anderson K, Gillingham K, Matas A. Kidney transplants from living donors: how donation affects family dynamics. Adv Ren Replace Ther. 1998;5(2):89-97.

31. Jordan J, Sann U, Janton A, Gossmann J, Kramer W, Kachel HG, et al. Living kidney donors' long-term psychological status and health behavior after nephrectomy - a retrospective study. J Nephrol. 2004;17(5):728-35.

32. Minz M, Udgiri N, Sharma A, Heer MK, Kashyap R, Nehra R, et al. Prospective psychosocial evaluation of related kidney donors: Indian perspective. Transplant Proc. 2005;37(5):2001-3.

33. Sharp J, McRae A, McNeill Y. Decision making and psychosocial outcomes among living kidney donors: a pilot study. Prog Transplant. 2010;20(1):53-7.

34. von Zur-Muhlen B, Berglund D, Yamamoto S, Wadstrom J. Single-Centre long-term follow-up of live kidney donors demonstrates preserved kidney function but the necessity of a structured lifelong follow-up. Ups J Med Sci. 2014;119(3):236-41.

35. Kroenke K, Spitzer RL, Williams JB, Monahan PO, Lowe B. Anxiety disorders in primary care: prevalence, impairment, comorbidity, and detection. Ann Intern Med. 2007;146(5):317-25.

36. Arroll B, Goodyear-Smith F, Crengle S, Gunn J, Kerse N, Fishman T, et al. Validation of PHQ-2 and PHQ-9 to screen for major depression in the primary care population. Ann Fam Med. 2010;8(4):348-53.

37. Kroenke K, Spitzer RL, Williams JB. The PHQ-9: validity of a brief depression severity measure. J Gen Intern Med. 2001;16(9):606-13.

38. Agency for Healthcare Research and Quality. Chapter 3: Creation of New Race-Ethnicity Codes and SES Indicators for Medicare Beneficiaries U.S. Department of Health \& Human Services; 2008 [updated January 2008; cited 2015 December 4]. Available from: http://archive.ahrq.gov/research/findings/ final-reports/medicareindicators/medicareindicators $3 . \mathrm{html}$.

39. Zou G. A modified poisson regression approach to prospective studies with binary data. Am J Epidemiol. 2004;159(7):702-6.

40. Louis TA, Zeger SL. Effective communication of standard errors and confidence intervals. Biostatistics. 2009;1:1-2.

41. Tsunoda T, Yamashita R, Kojima Y, Takahara S. Risk factors for depression after kidney transplantation. Transplant Proc. 2010;42(5):1679-81.

42. Spijker J, de Graaf R, Bijl RV, Beekman AT, Ormel J, Nolen WA. Duration of major depressive episodes in the general population: results from the Netherlands mental health survey and incidence study (NEMESIS). Brit J Psychiatry. 2002;181:208-13.

43. Eaton WW, Shao H, Nestadt G, Lee HB, Bienvenu OJ, Zandi P. Populationbased study of first onset and chronicity in major depressive disorder. Arch Gen Psychiatry. 2008;65(5):513-20.

44. Mjoen G, Stavem K, Westlie L, Midtvedt K, Fauchald P, Norby G, et al. Quality of life in kidney donors. Am J Transplant. 2011;11(6):1315-9.

45. Hart A, Smith JM, Skeans MA, Gustafson SK, Stewart DE, Cherikh WS, et al. OPTN/SRTR 2015 annual data report: kidney. Am J Transplant. 2017;17(Suppl 1):21-116.

Ready to submit your research? Choose BMC and benefit from:

- fast, convenient online submission

- thorough peer review by experienced researchers in your field

- rapid publication on acceptance

- support for research data, including large and complex data types

- gold Open Access which fosters wider collaboration and increased citations

- maximum visibility for your research: over $100 \mathrm{M}$ website views per year

At $\mathrm{BMC}$, research is always in progress.

Learn more biomedcentral.com/submissions 